\title{
Parametric test for non-normally distributed continuous data: For and against
}

\author{
Umesh Wadgave $^{1}$, Mahesh Ravindra Khairnar ${ }^{2}$
}

\begin{abstract}
${ }^{1}$ MDS, Associate Professor, Department of Public Health Dentistry, Bharati Vidyapeeth Deemed University Dental College and Hospital, Sangli, Maharashtra, India

${ }^{2}$ MDS, Assistant Professor, Department of Public Health Dentistry, Bharati Vidyapeeth Deemed University Dental College and Hospital, Sangli, Maharashtra, India
\end{abstract}

\section{Type of article: Editorial}

\begin{abstract}
Choosing between parametric and non-parametric statistical tests for analysis of non-normally distributed continuous data is a long-standing controversy. Conventionally, it is recommended to use non-parametric tests but few others suggest using the parametric test. This article evaluates the simulation studies comparing the parametric tests with non-parametric tests in analysing the non-normally distributed continuous data. Nonparametric tests are recommended only when data is highly skewed and log transformation technique cannot change it to normal distribution. However, in most other situations parametric tests are more powerful in analysing non-normally distributed continuous data.
\end{abstract}

Keywords: Biostatistics, Data analyses, Non-parametric statistics, Normal distribution

\section{Note:}

This is a solicited editorial and Dr. Umesh Wadgave is an Associate Editor of Electronic Physician. Because of presence of non-normally distributed data in some of the manuscripts submitted to biomedical journals- and to Electronic Physician, the journal has invited the authors of this editorial, to discuss on the long-standing controversy issue of choosing between parametric and non-parametric statistical tests.

\section{Acronyms / Abbreviations:}

WMW: Wilcoxon-Mann-Whitney, also called the Mann-Whitney-Wilcoxon (MWW) or the Mann-Whitney U test; WSR: Wilcoxon signed-rank

\section{INTRODUCTION}

It is a long-standing debate whether parametric tests are applicable to non-normally distributed continuous data or not (1). Conventionally, it is recommended that for applying parametric statistical methods, data should be normally distributed. If not, alternative non-parametric statistical methods should be employed (2). Unfortunately, choosing non-parametric over parametric statistical methods is not that straightforward. We have to consider several other factors while choosing statistical methods such as the probability of committing type I or type II error (1). The only way to resolve this controversy is to evaluate the evidence of several simulation studies comparing the potential of parametric statistics with non-parametric statistics for non-normally distributed continuous data. This article

\section{Corresponding author:}

Associate Professor Dr. Umesh Wadgave, Department of Public Health Dentistry, Bharati Vidyapeeth Deemed University Dental College and Hospital, Walnesswadi, Sangli, Maharashtra, India (Pin: 416416).

Tel: +91-8805835602, Email: dr.w.umesh@gmail.com Umesh Wadgave

Received: January 15, 2019, Accepted: March 11, 2019, Published: June 2019

iThenticate screening: March 11, 2019, English editing: March 15, 2019, Quality control: April 02, 2019

This article has been reviewed / commented by three experts

Funding: This article did not receive any specific grant from funding agencies in the public, commercial or not-forprofit sectors.

Ethics approval: Not applicable, as this article is an Editorial and don't involve humans or animals.

(C) 2019 The Authors. This is an open access article under the terms of the Creative Commons Attribution-NonCommercialNoDerivs License, which permits use and distribution in any medium, provided the original work is properly cited, the use is non-commercial and no modifications or adaptations are made. 
reviewed the simulation studies comparing the properties of parametric statistics with non-parametric statistics and attempts to suggest the appropriate statistical design for non-normally distributed continuous data.

\section{EVIDENCE AGAINST PARAMETRIC STATISTICS}

Non-parametric tests are considered more powerful for the analysis of studies with the small sample and/or nonnormally distributed data. Two simulation studies have demonstrated that both Wilcoxon-Mann-Whitney (WMW) and Wilcoxon's signed-ranks test are more powerful than the unpaired t-test and paired t-test respectively in analysing non normally distributed data $(3,4)$. Another study showed, WMW is asymptotically more powerful for $\mathrm{t}$ distributions with degrees of freedom less than 18 (5). Studies have demonstrated that in analysing extremely skewed data Wilcoxon signed-rank (WSR) test held greater power advantages than paired t-test, and t-test was inefficient to control Type I and II error $(6,7)$.

\section{EVIDENCE FAVOURING PARAMETRIC STATISTICS}

Basically, the parametric test depends on the assumption of the normal distribution of the sample means, not of data (8). Therefore, the assumption of normality cannot be considered a very strong requirement for parametric tests' application. According to the central limit theorem, in small sample sizes, sampling distribution of means will be normal if the sample data are approximately normal and in large samples [>30 or 40], the sampling distribution of means tends to be normal, regardless of the shape of the data (9). Even the use of normality tests to check deviation from normal distribution of data are not considered valid because they have less power in small sample sizes and they become very sensitive in large sample sizes. It should also be noted that parametric tests are not affected by small deviation in normal distribution of continuous data $(1,10,12)$. Misconception about normality assumption (i.e. distribution of sample means not of data), high tendency of sample means for normal distribution, limitation of normality tests to detect deviation in normal distribution and robustness of parametric tests to small deviation, favours the application of parametric tests for the analysis on non-normally distributed continuous data.

Several simulation studies have demonstrated that parametric statistics such as t-test, modified t-test, and Welch $\mathrm{U}$ test were more robust than their non-parametric counterparts to type I error, type II error and the power calculations for non-normally distributed data with different variances and sample sizes $(6,7,12-15)$. On the other hand, Analysis of covariance test was more efficient than Man-Whitney test in analysing log transformation of extremely skewed data of a randomized trial (2).

Parametric tests have a few other advantages over non-parametric methods such as; first, for very small sample sizes of 2 or 3, parametric test have the ability to show the significant difference which is not possible with nonparametric tests., second, highly skewed continuous data can be converted to normal distribution with log transformation technique before employing parametric tests, and third, estimates and confidence intervals can easily be produced by parametric tests, which is not directly possible by non-parametric tests (16).

\section{CONCLUSIONS}

The existing evidence from simulation studies suggests that parametric methods are preferred over non-parametric in most situations while analysing non-normally distributed continuous data. Even though non-parametric tests are independent of normality assumption, they depend on equal shape and variance of the two distributions [homoscedasticity] (12). So, non-parametric tests should only be considered for the continuous data when the distribution is highly skewed and log transformation cannot change it to normal distribution and when normality of these data cannot be assumed from reports of these data elsewhere (16). Considering the limitation of normality tests' application to both large and small sample sizes, it is advised to assess the magnitude of skewness of data distribution with graphical methods.

\section{Funding:}

This article did not receive any specific grant from funding agencies in the public, commercial or not-for-profit sectors.

\section{Conflict of Interest:}

There is no conflict of interest to be declared.

\section{Authors' contributions:}

Both authors contributed to this article equally. Both authors read and approved the final manuscript. 


\section{References:}

1) Fagerland MW. t-tests, non-parametric tests, and large studies--a paradox of statistical practice? BMC Med Res Methodol. 2012 Jun 14;12:78. PubMed PMID: 22697476. PMCid: PMC3445820. DOI: 10.1186/14712288-12-78

2) Vickers AJ. Parametric versus non-parametric statistics in the analysis of randomized trials with nonnormally distributed data. BMC Med Res Methodol. 2005 Nov 3;5:35. PubMed PMID: 16269081, PMCid: PMC1310536, DOI: 10.1186/1471-2288-5-35

3) Blair RC, Higgins JJ. A Comparison of the Power of Wilcoxon's Rank-Sum Statistic to That of Student's t Statistic under Various Nonnormal Distributions. J Educ Stat. 1980. 5[4]:309-335. DOI: 10.3102/10769986005004309

4) Blair RC, Higgins JJ. Comparison of the Power of the Paired Samples T test to that of Wilcoxon's SignedRanks Test Under Various Population Shapes. Psychol Bull. 1985. 97[1]:119-28. DOI: 10.1037/00332909.97.1.119

5) Fay MP, Proschan MA. Wilcoxon-Mann-Whitney or t-test? On assumptions for hypothesis tests and multiple interpretations of decision rules. Stat Surv. 2010;4:1-39. PMid: 20414472, PMCid: PMC2857732. DOI: $10.1214 / 09-S S 051$

6) Sawilowsky SS, Hillman SB. Power of the independent samples t test under a prevalent psychometric measure distribution. J Consult Clin Psychol. 1992 Apr;60[2]:240-3. PMID: 1592953. DOI: 10.1037/0022006X.60.2.240

7) Sawilowsky SS, Blair RC. A more realistic look at the robustness and Type II error properties of the $t$ test to departures from population normality. Psychol Bull. 1992;111[2]:352-360. DOI: 10.1037/00332909.111.2.352

8) Wadgave U, Khairnar MR. Parametric tests for Likert scale: For and against. Asian J Psychiatr. 2016;24:67-68. PMID: 27931911

9) Ghasemi A, Zahediasl S. Normality tests for statistical analysis: A guide for non-statisticians. Int J Endocrinol Metab. 2012. 10[2]: 486-489. PMID: 23843808, PMCid: PMC3693611, DOI: $10.5812 / \mathrm{ijem} .3505$

10) Öztuna D, Elhan AH, Tüccar E. Investigation of four different normality tests in terms of type 1 error rate and power under different distributions. Turkish J Med Sci. 2006. 36 [3]: 171-176.

11) Razali NM, Wah YB. Power comparisons of Shapiro-Wilk, Kolmogorov-Smirnov, Lilliefors, and Anderson-Darling tests. J Stat Model Anal. 2011. 2:21-33.

12) Skovlund E, Fenstad GU. Should we always choose a nonparametric test when comparing two apparently nonnormal distributions? J Clin Epidemiol. 2001 Jan;54[1]:86-92. PMID: 11165471, DOI: 10.1016/S08954356(00)00264-X

13) Zimmerman DW. Invalidation of parametric and nonparametric statistical tests by concurrent violation of two assumptions. J Exp Educ. 1998. 67[1]:55-68. DOI: 10.1080/00220979809598344

14) Zimmerman DW, Zumbo BD. Parametric Alternatives to the Student $T$ Test under Violation of Normality and Homogeneity of Variance. Percept Mot Skills. 1992;74[3]:835. DOI: 10.2466/pms.1992.74.3.835

15) Fagerland MW, Sandvik L, Mowinckel P. Parametric methods outperformed non-parametric methods in comparisons of discrete numerical variables. BMC Med Res Methodol. 2011 Apr 13;11:44. DOI: 10.1186/1471-2288-11-44

16) Bland JM, Altman DG. Statistics Notes: Analysis of continuous data from small samples. BMJ. 2009. 338:a3166. DOI: 10.1136/bmj.a3166 